\title{
Author Correction: Characterization of Truncated $d s z$ Operon Responsible for Dibenzothiophene Biodesulfurization in Rhodococcus sp. FUM94
}

\author{
Somayeh Khosravinia ${ }^{1} \cdot \operatorname{Mahmood~A.~}$ Mahdavi $^{1}$ • \\ Reza Gheshlaghi ${ }^{1} \cdot$ Hesam Dehghani ${ }^{2,3}$
}

Published online: 25 January 2018

(C) Springer Science+Business Media, LLC, part of Springer Nature 2018

\author{
Author Correction: Appl Biochem Biotechnol \\ https://doi.org/10.1007/s12010-017-2596-z
}

The original version of this article unfortunately contained a mistake in the caption of Figs. 5 and 6 . Their respective caption should read as:

Fig. 5 Desulfurization activity of resting Rhodococcus sp. FUM94 cells with different dibenzothiophene (DBT) concentrations. The biocatalyst concentration was $2 \mathrm{~g}^{-1}$ and phase ratio 1. Biodesulfurization (BDS) yield (solid line) and the specific production rate $q_{\mathrm{p}}$ (dashed line) are shown. Data points are the average of triplicate experiments. Error bars indicate the error margin with $95 \%$ confidence level

Fig. 6 Desulfurization activity of resting Rhodococcus sp. FUM94 cells with different biocatalyst concentrations. Dibenzothiophene (DBT) concentration was $271 \mu \mathrm{M}$ and phase ratio 1. Biodesulfurization (BDS) yield (solid line) and the specific production rate $q_{\mathrm{p}}$ (dashed line) are shown. Data points are the average of triplicate experiments. Error bars indicate the error margin with $95 \%$ confidence level

The online version of the original article can be found at https://oi.org/10.1007/s12010-017-2596-z

Mahmood A. Mahdavi

mahdavi@um.ac.ir

1 Department of Chemical Engineering, Ferdowsi University of Mashhad, Azadi Square, Pardis Campus, Mashhad 9177948944, Iran

2 Embryonic and Stem Cell Biology and Biotechnology Research Group, Institute of Biotechnology, Ferdowsi University of Mashhad, Azadi Square, Mashhad 9177948944, Iran

3 Division of Biotechnology, Faculty of Veterinary Medicine, Ferdowsi University of Mashhad, Azadi Square, Mashhad 9177948944, Iran 